\title{
Sumário
}

\section{Artigos Científicos}

Qualidade e sustentabilidade: sistemas de certificação do café sob a ótica dos Pilares da

Qualidade

Paulo Henrique Montagnana Vicente Leme, Cintia Loos Pinto

Diagnóstico da qualidade físico-química do solo sob diferentes usos e manejos no sul de

Minas Gerais

Cláudia Heluani de Sousa Antunes, Leidiane Portugal, João Paulo Maia, Renata Amato Moreira, Bruno Montoani Silva, Walbert Júnior Reis dos Santos

Crescimento e produtividade de híbridos de milho semeados na segunda safra em Sinop (MT)

Ivan Vilela Andrade Fiorini, Cassiano Spaziani Pereira, Ezequiel Giese, Hélcio Duarte Pereira, Felipe Ribeiro Resende, Adriano Alves da Silva

Envelhecimento acelerado de sementes de alface produzidas no manejo orgânico em cultivo protegido e a céu aberto

Antônio de Amorum Brandão, Higino Marcos Lopes

Seletividade de tembotrione aplicado em diferentes estádios fenológicos da cultura do milho safrinha

Luciano Bueno Mançanares, Acácio Gonçalves Netto, Jeisiane de Fátima Andrade, Jéssica Cursino Presoto, Ludimila Justina Ferreira da Silva, Saul Jorge Pinto de Carvalho

Influência das variáveis climáticas na incidência da varíola do mamoeiro "Sunrise Golden" em diferentes densidades de cultivo sob manejo orgânico de produção

Thiago Cunha Silverio, Luiz Aurélio Peres Martelleto, Nilson Costa Rezende, Herton Chimelo Pivoto, Livia Israel Ferreira

Alternative ground cover in lettuce production under tropical climate conditions

Ernandes Guedes Moura, Fábio de Sousa Silva, Rodrigo Fonseca da Silva, Fabrício Ribeiro Andrade, Jodean Alves da Silva, Ana Teresa Pereira da Silva

Formas e estádios de aplicação de adubação nitrogenada no desenvolvimento e produtividade da soja

Cassiano Spaziani Pereira, Marcos Guilherme Trentin Filho, Ivan Vilela Andrade Fiorini, Helcio Duarte Pereira,

José Roberto Rocha, Anderson Lange

Avaliação qualiquantitativa de biogás em unidade de produção de suínos e seu reaproveitamento energético

Diego Bedin Marin, Alessandro Veira Veloso, Matheus Campos Mattioli, Jefferson Francisco Soares

Relação entre cobertura e temperatura do solo em região periurbana do Cerrado Renato Carneiro Fernandes da Silva, César Silva Lopes, Francienne Góis Oliveira, André Luís Teixeira Fernandes, Leonardo Campos de Assis 